\title{
Intravenous tranexamic acid use in revision total joint arthroplasty: a meta-analysis
}

This article was published in the following Dove Press journal:

Drug Design, Development and Therapy

\author{
Feng-Chih Kuo' \\ Pao-Yen Lin ${ }^{2}$ \\ Jun-Wen Wang' \\ Po-Chun Lin' \\ Mel S Lee' \\ Antonia $\mathrm{F} \mathrm{Chen}{ }^{3}$ \\ 'Department of Orthopaedic Surgery, \\ Kaohsiung Chang Gung Memorial \\ Hospital, College of Medicine, \\ Chang Gung University, Kaohsiung, \\ Taiwan; ${ }^{2}$ Department of Psychiatry, \\ Kaohsiung Chang Gung Memorial \\ Hospital, College of Medicine, Chang \\ Gung University, Kaohsiung, Taiwan; \\ ${ }^{3}$ Department of Orthopaedic Surgery, \\ Brigham and Women's Hospital, \\ Harvard Medical School, Boston, \\ MA, USA
}

Purpose: Massive perioperative blood loss in complex revision total joint arthroplasty (TJA) often requires blood transfusions. Tranexamic acid (TXA) has been used in elective primary TJA to minimize blood loss and transfusions. The purpose of this meta-analysis was to evaluate the safety and efficacy of intravenous TXA in revision TJA.

Methods: A literature search of PubMed, Scopus, and the Cochrane Controlled Trials Register was performed to identify studies published between January 2000 and May 2017. All randomized controlled trials (RCTs) and retrospective cohort observational studies evaluating the efficacy of intravenous TXA during revision total knee arthroplasty (TKA) and total hip arthroplasty (THA) were included. The mean differences (MDs) of blood loss, hemoglobin (Hb) change, and red blood cell (RBC) units transfused were compiled, and ORs of transfusion and venous thromboembolism (VTE) events in TXA and control groups were calculated.

Results: Seven studies involving 930 patients were included (501 TXA vs 429 control). Intravenous TXA use had a significantly less blood transfusion $(\mathrm{OR}=0.20,95 \% \mathrm{CI}=0.11-0.34$, $P<0.001$ ), lower $\mathrm{Hb}$ drop ( $\mathrm{MD}=-0.88,95 \% \mathrm{CI}=-1.31$ to $-0.44, P<0.001$ ), and less number of $\mathrm{RBC}$ units transfused $(\mathrm{MD}=-0.44,95 \% \mathrm{CI}=-0.65$ to $-0.24, P<0.001)$ compared to control in the postoperative period. No significant difference was seen in blood loss $(\mathrm{MD}=-245,95 \% \mathrm{CI}=-556$ to $66, P=0.12)$ and VTE events $(\mathrm{OR}=0.57,95 \% \mathrm{CI}=0.13-2.42, P=0.45)$ between groups.

Conclusion: Our meta-analysis suggests that intravenous administration of TXA can significantly reduce blood transfusion requirements following revision TJA, without increasing the risk of VTE. However, due to the variation in included studies, larger RCTs are required to draw firm conclusions.

Keywords: tranexamic acid, revision arthroplasty, transfusion, venous thromboembolism, meta-analysis

\section{Introduction}

More revision total joint arthroplasties (TJAs) are being performed as the number of primary TJAs has increased. ${ }^{1}$ Revision TJA is often associated with greater blood loss, which may result in increased transfusion requirements. Allogenic red blood cell (RBC) transfusions can lead to transfusion reactions, are a risk factor for periprosthetic joint infections, and may increase costs. Blood-conserving techniques, such as the use of antifibrinolytic agents, have been implemented to decrease blood loss and blood transfusion rates. ${ }^{2}$

Tranexamic acid (TXA) is a commonly used antifibrinolytic in orthopedic surgeries that works by blocking the lysine-binding sites on plasminogen molecules, inhibiting the formation of plasmin. ${ }^{3}$ TXA can be administered intravenously (IV), topically in the surgical wound, or combined. All forms of TXA administration have successfully reduced blood loss after primary total knee arthroplasty (TKA) and total
Correspondence: Antonia F Chen Department of Orthopaedic Surgery, Brigham and Women's Hospital, Harvard Medical School, 75 Francis Street, Boston, MA, USA

Tel + I 6175255935

Fax +I 6172645226

Email uafchen@bwh.harvard.edu
Drug Design, Development and Therapy 2018:12 3163-3170

3163

Dovepress f $y$ in $\mathbf{0}$

http://dx.doi.org/1 0.21477/DDDT.S175407 (c) (1) (5) 2018 kuo et al. This work is published and licensed by Dove Medical Press Limited. The full terms of this license are available at https://www.dovepress.com/terms.php

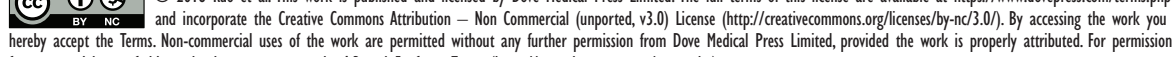
hereby accept the Terms. Non-commercial uses of the work are permitted without any further permission from Dove Medis
for commercial use of this work, please see paragraphs 4.2 and 5 of our Terms (https://www.dovepress.com/terms.php). 
hip arthroplasty (THA) over the last decade. ${ }^{3}$ IV TXA has been widely studied and has been shown to reduce blood loss and transfusion requirements in revision TJA..$^{4-14}$ However, few of these studies characterized changes in hemoglobin $\mathrm{Hb}$ ) or venous thromboembolism (VTE) complications. Additionally, some of these studies were poorly designed and had a low power or inconclusive results. While various small studies have evaluated the use of IV TXA in revision TJA, there have been no studies to date that have compiled data from multiple studies.

Thus, the purpose of this meta-analysis was to investigate the efficacy of TXA in revision TJA, specifically assessing the following outcome measurements: 1) blood transfusion rate; 2) Hb change; 3) mean units of RBC transfused; 4) blood loss; and 5) VTE complications.

\section{Materials and methods \\ Data and literature sources}

Two independent reviewers searched for eligible studies between January 2000 and May 2017 in PubMed at the National Library of Medicine, Scopus, and Cochrane Controlled Trials Register. The search was performed by using the search terms (tranexamic acid) AND (revision) AND (hip or knee), without limitation in language. The references of relevant articles and review articles in this area were searched for citations not indexed in abovementioned databases. The titles and abstracts of studies obtained by this search strategy were screened by reviewers to determine if studies were potentially eligible for inclusion in this meta-analysis. The following studies were excluded based on titles and abstracts alone: review articles, non-human studies, articles commenting on other studies or case reports, and studies not mentioning TXA. In cases of disagreement, a third person was consulted to evaluate the articles.

\section{Study selection and data extraction}

After primary screening of titles and abstracts, the remaining studies comparing administration of IV TXA vs controls were evaluated for the following: 1) patients undergoing unilateral revision THA or TKA; 2) the use of IV TXA; and 3) outcome measurements including number of RBC units transfused, number of patients who received a blood transfusion, blood transfusion rate, mean and standard deviation values of postoperative blood loss via drainage (BLD), estimated blood loss (EBL), total blood loss (TBL) and change in $\mathrm{Hb}$ levels before and after surgery, and VTE complications. The full text of articles was obtained if the title and abstract did not supply adequate information, and authors of individual trials were contacted directly to provide further information when necessary. Disagreements were resolved by consensus or consultation with the senior author, and studies were excluded if there were unavailable data. The process of study selection is described in Figure 1.

\section{Assessment of methodological quality}

To assess the methodological quality of included studies, two reviewers independently assessed the methodological quality of the prospective randomized controlled trials (RCTs) using the Jadad scale, including randomization, blinding, withdrawals and dropouts, inclusion and exclusion criteria, adverse reactions, and statistical analysis. A scale of 0 (very poor) to 5 (rigorous) was used to assess the methodological strength of a clinical trial. ${ }^{15}$ The Newcastle-Ottawa Scale (NOS), as recommended by the Cochrane Non-Randomized Studies Methods Working Group, was used to assess retrospective or prospective cohort observational studies based on three criteria: the selection of study groups, the comparability of groups, and the ascertainment of either exposure or outcome of interest for case-control and cohort studies. The NOS ranged between 0 and 9 , with $7+$ points considered as a "high-quality" study. ${ }^{16}$ Any unresolved disagreements between reviewers were resolved by consultation with a third investigator.

\section{Data synthesis and analysis}

The Comprehensive Meta-Analysis Software, version 2 (Biostat, Englewood, NJ, USA) was used to analyze the selected studies. The treatment effect for continuous data was expressed as mean difference (MD) with a $95 \%$ CI. The treatment effect for dichotomous data was expressed as OR with a $95 \%$ CI. The data from included studies were synthesized by using a random-effects model. Missing data were sought from the authors. When this was not possible or data were missing due to loss of follow-up, intention-to-treat principles were used.

Heterogeneity was determined by estimating the proportion of between-study inconsistencies due to actual differences between studies, rather than differences due to random error or chance using the $I^{2}$ statistic, with values of $25 \%, 50 \%$, and $75 \%$ considered as low, moderate, and high heterogeneity, respectively. A $P$-value of $<0.1$ and an $I^{2}$ value of $>50 \%$ were considered suggestive of statistical heterogeneity. It did not imply that there was necessarily homogeneity, as there may have been insufficient power to be able to detect heterogeneity. When the data allowed, we performed subgroup analysis of the trials according to the type of surgery location (hip or knee). 


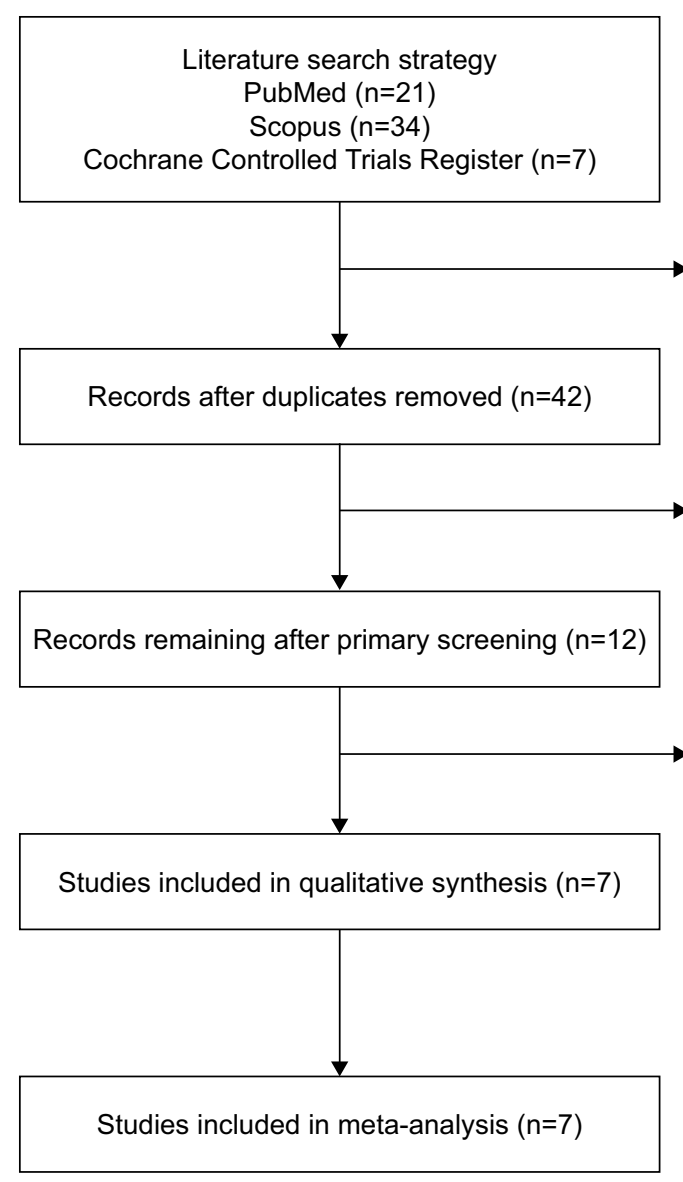

Records excluded for duplication $(n=20)$

Records excluded after primary screening of title and abstract

*Did not meet criteria $(n=29)$

*Comments on other studies or case reports $(n=1)$

Full articles excluded for unavailable data $(n=5)$

Figure I The flow chart of literature screening.

\section{Results}

\section{Literature screening}

There were 62 articles for initial consideration in the metaanalysis, and a total of 20 studies were excluded due to duplication. Based on title and abstract evaluation, 30 studies were excluded because they did not meet the specified criteria. When the text of the remaining 12 studies was examined, five of them were excluded because they did not have available data for meta-analysis (Figure 1). The remaining seven studies (one RCT, one prospective cohort observational study, and five retrospective cohort observational studies) were included in the meta-analysis, which included 501 revision TJA patients (149 revision THAs and 352 revision TKAs) who were administered intravenous TXA and 429 revision TJA control patients (91 revision THAs and 338 revision TKAs) who did not receive TXA. Different dosages of TXA were used in the studies (Table 1). In terms of dosages, the most commonly used doses of IV TXA were $10 \mathrm{mg} / \mathrm{kg}$ before skin incision and $10 \mathrm{mg} / \mathrm{kg}$ or $1 \mathrm{~g} 2-3$ hours after the operation in revision THA. In revision TKA, IV TXA with a dose of $10-20 \mathrm{mg} / \mathrm{kg}$ before deflation of the tourniquet was commonly used. Only one RCT study ${ }^{5}$ in this meta-analysis had a wider range of blood transfusion $(\mathrm{Hb}<10 \mathrm{~g} / \mathrm{dL}$ and hematocrit $[\mathrm{Hct}]<30 \%$ ) compared with the other six observational studies. This RCT study ${ }^{5}$ also lacked information about the change in $\mathrm{Hb}$ levels.

\section{Methodological quality of included studies}

Table 2 summarizes the quality assessment of the selected studies. One study was an RCT with a Jadad score of 5, demonstrating high quality. Among the other six nonrandomized studies, the NOS score ranged from 6 to 8 , which indicated acceptable quality for these studies.

\section{Allogenic blood transfusion rate}

All seven studies provided data on the number of patients who underwent blood transfusions. A total of 75 (15.0\%) transfusions occurred in the TXA group compared with 166 (38.7\%) transfusions in the control group. Five retrospective cohort observational studies favored lower allogenic blood transfusion rate in patients with IV TXA compared with the control group. 
Table I Characteristics of included studies

\begin{tabular}{|c|c|c|c|c|c|c|}
\hline $\begin{array}{l}\text { Study, } \\
\text { year }\end{array}$ & Study type & Location & $\begin{array}{l}\text { No TXA/ } \\
\text { control }\end{array}$ & Intervention & VTE prophylaxis & $\begin{array}{l}\text { Blood transfusion } \\
\text { protocol }\end{array}$ \\
\hline $\begin{array}{l}\text { Gill et al, }{ }^{5} \\
2009\end{array}$ & RCT & Hip & $5 / 5$ & $\begin{array}{l}\text { TXA I } 0 \mathrm{mg} / \mathrm{kg} \text { IV before } \\
\text { induction of anesthesia, } \\
\text { then I } \mathrm{mg} / \mathrm{kg} / \mathrm{h} \text { infusion until } \\
\text { wound closure }\end{array}$ & Warfarin+mechanical & $\mathrm{Hb}<10 \mathrm{~g} / \mathrm{dL}$ and $\mathrm{Hct}<30 \%$ \\
\hline $\begin{array}{l}\text { Kazi et al, } \\
2012\end{array}$ & $\begin{array}{l}\text { Prospective cohort } \\
\text { observational study }\end{array}$ & Hip & $30 / 30$ & $\begin{array}{l}\text { TXA } 10 \mathrm{mg} / \mathrm{kg} \text { IV } 30 \text { minutes } \\
\text { before operation and } \\
10 \mathrm{mg} / \mathrm{kg} \mathrm{IV} \mathrm{further} \mathrm{dose} \\
\text { after } 3 \text { hours from operation }\end{array}$ & LMWH & $\begin{array}{l}\mathrm{Hb}<7 \mathrm{~g} / \mathrm{dL} \text { or } \mathrm{Hb}<8 \mathrm{~g} / \mathrm{dL} \\
\text { with cardiovascular disease }\end{array}$ \\
\hline $\begin{array}{l}\text { Park et al, }{ }^{12} \\
2016\end{array}$ & $\begin{array}{l}\text { Retrospective cohort } \\
\text { observational study }\end{array}$ & Hip & $114 / 56$ & $\begin{array}{l}\text { TXA I g IV at incision and } \\
\text { TXA I g IV further dose } \\
\text { after } 2 \text { hours from operation }\end{array}$ & Unknown & $\begin{array}{l}\mathrm{Hb}<7 \mathrm{~g} / \mathrm{dL} \text { or } \mathrm{Hb}<8 \mathrm{~g} / \mathrm{dL} \\
\text { with } \mathrm{ACS}, \mathrm{CHF} \text {, or requiring } \\
\text { oxygen }\end{array}$ \\
\hline $\begin{array}{l}\text { Aguilera et al, } \\
2012\end{array}$ & $\begin{array}{l}\text { Retrospective cohort } \\
\text { observational study }\end{array}$ & Knee & $19 / 49$ & $\begin{array}{l}\text { TXA I g IV I5-30 minutes } \\
\text { before inflation of the } \\
\text { tourniquet and TXA I g } \\
\text { IV before deflation of the } \\
\text { tourniquet }\end{array}$ & LMWH & $\begin{array}{l}\mathrm{Hb}<8 \mathrm{~g} / \mathrm{dL} \text { or } \mathrm{Hb}<8.5 \mathrm{~g} / \mathrm{dL} \\
\text { with heart disease or older } \\
\text { than } 70 \text { years } \\
\mathrm{Hb} \text { between } 8.5 \text { and } 9 \mathrm{~g} / \mathrm{dL} \\
\text { (does not tolerate sitting) }\end{array}$ \\
\hline $\begin{array}{l}\text { Smit et al, } \\
2013\end{array}$ & $\begin{array}{l}\text { Retrospective cohort } \\
\text { observational study }\end{array}$ & Knee & $246 / 178$ & $\begin{array}{l}\text { TXA } 20 \mathrm{mg} / \mathrm{kg} \text { IV before } \\
\text { deflation of the tourniquet }\end{array}$ & LMWH & $\begin{array}{l}\mathrm{Hb}<7 \mathrm{~g} / \mathrm{dL} \text { or symptomatic } \\
\text { or } \mathrm{Hb} \text { between } 8 \text { and } 9 \mathrm{~g} / \mathrm{dL} \\
\text { with cardiac history }\end{array}$ \\
\hline $\begin{array}{l}\text { Samujh et al, }{ }^{10} \\
2014\end{array}$ & $\begin{array}{l}\text { Retrospective cohort } \\
\text { observational study }\end{array}$ & Knee & $43 / 68$ & $\begin{array}{l}\text { TXA } 10 \mathrm{mg} / \mathrm{kg} \text { IV I } 0 \text { minutes } \\
\text { before deflation of the } \\
\text { tourniquet }\end{array}$ & Rivaroxaban & $\begin{array}{l}\mathrm{Hb}<8 \mathrm{~g} / \mathrm{dL} \text { with symptoms } \\
\text { of anemia }\end{array}$ \\
\hline $\begin{array}{l}\text { Ortega-Andreu } \\
\text { et al, }{ }^{13} \\
2016\end{array}$ & $\begin{array}{l}\text { Retrospective cohort } \\
\text { observational study }\end{array}$ & Knee & $44 / 43$ & $\begin{array}{l}\text { TXA I } 5 \mathrm{mg} / \mathrm{kg} \text { IV before } \\
\text { deflation of the tourniquet } \\
\text { and } 15 \mathrm{mg} / \mathrm{kg} \text { IV further dose } \\
\text { after } 3 \text { hours after surgery }\end{array}$ & Unknown & $\begin{array}{l}\mathrm{Hb}<8 \mathrm{~g} / \mathrm{dL} \text { or } \mathrm{Hb}<10 \mathrm{~g} / \mathrm{dL} \\
\text { with symptoms of anemia or } \\
\text { cardiac history }\end{array}$ \\
\hline
\end{tabular}

Abbreviations: ACS, acute coronary syndrome; CHF, congestive heart failure; Hb, hemoglobin; Hct, hematocrit; IV, intravenously; LMWH, low-molecular-weight heparin; RCT, randomized controlled trial; TXA, tranexamic acid; VTE, venous thromboembolism.

However, one $\mathrm{RCT}^{5}$ and one retrospective cohort observational study $^{8}$ did not favor IV TXA to reduce the allogenic blood transfusion rate. The proportion of patients who received allogenic blood transfusion was lower in the TXA group ( $\mathrm{OR}=0.20,95 \% \mathrm{CI}=0.11-0.34, P<0.001, I^{2}=58 \%$; Figure 2 ). Three studies were specific for revision THA, and four studies were specific for revision TKA. The revision THA subgroup had a significantly lower allogenic blood transfusion rate compared to control $(\mathrm{OR}=0.19,95 \% \mathrm{CI}=0.09-0.37, P<0.001$, $I^{2}=0 \%$ ). Similarly, the revision TKA subgroup also had a lower allogenic blood transfusion rate compared to control $(\mathrm{OR}=0.22$, $95 \% \mathrm{CI}=0.08-0.60, P=0.003, I^{2}=71 \%$ ).

\section{Change in $\mathrm{Hb}$ levels}

Of the seven studies, four compared the change in preoperative and postoperative $\mathrm{Hb}$ levels between revision TJA patients

Table 2 Quality of selected studies

\begin{tabular}{|c|c|c|c|c|c|}
\hline \multirow[t]{2}{*}{ Study, year } & \multirow[t]{2}{*}{ Study type } & \multicolumn{3}{|l|}{ Jadad scale } & \multirow{2}{*}{$\begin{array}{l}\text { Total } \\
\text { Score }\end{array}$} \\
\hline & & Randomization & Blinding & Cohort & \\
\hline \multirow[t]{3}{*}{ Gill et $\mathrm{al}^{5}, 2009$} & $\mathrm{RCT}$ & 2 & 2 & 1 & 5 \\
\hline & & \multicolumn{3}{|l|}{ NOS } & \\
\hline & & Selection & Comparability & Outcome & \\
\hline Kazi et al,7 2012 & Prospective cohort observational study & 3 & I & 2 & 6 \\
\hline Park et al, ${ }^{12} 2016$ & Retrospective cohort observational study & 4 & I & 2 & 7 \\
\hline Aguilera et al, ${ }^{8} 2012$ & Retrospective cohort observational study & 3 & 1 & 2 & 6 \\
\hline Smit et al, ${ }^{9} 2013$ & Retrospective cohort observational study & 4 & I & 3 & 8 \\
\hline Samujh et al, ${ }^{10} 2014$ & Retrospective cohort observational study & 4 & I & 2 & 7 \\
\hline Ortega-Andreu et al, ${ }^{13} 2016$ & Retrospective cohort observational study & 3 & 1 & 2 & 6 \\
\hline
\end{tabular}

Abbreviations: NOS, Newcastle-Ottawa Scale; RCT, randomized controlled trial. 


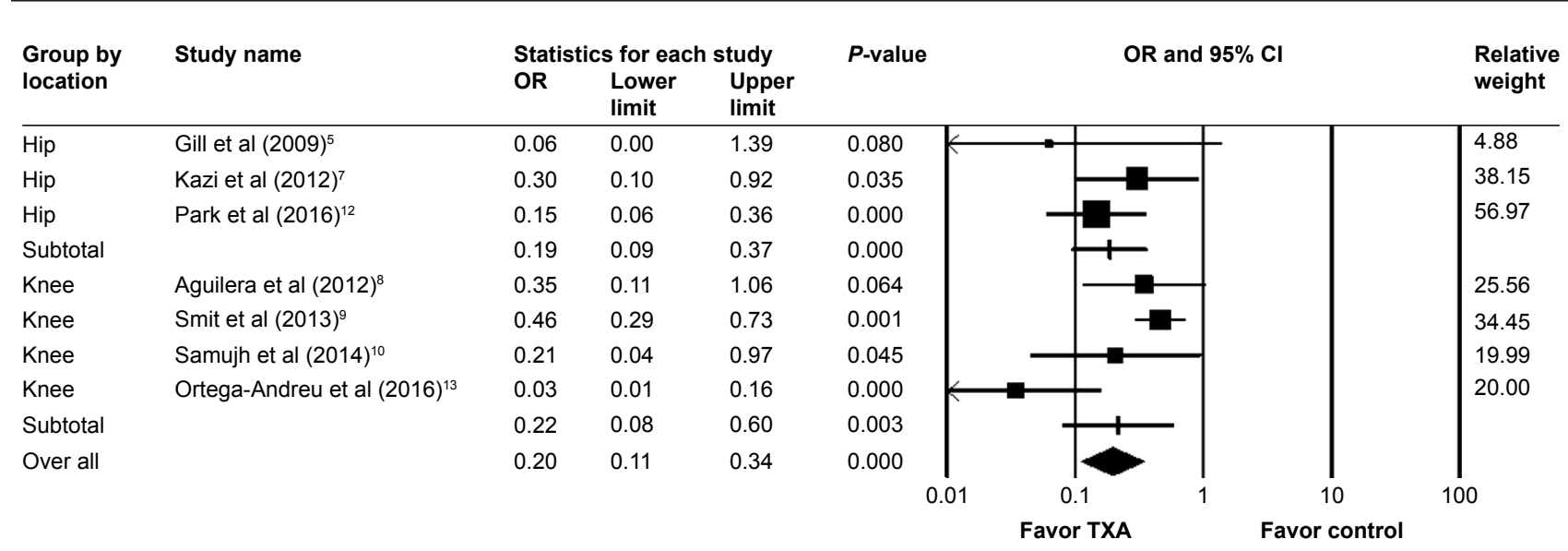

Figure 2 Results of aggregate analysis for comparison of allogenic blood transfusion rate between revision TJA patients who received intravenous TXA and control, including subgroup analysis by hip and knee.

Note: $95 \% \mathrm{Cl}$ shown as "Lower limit" and "Upper limit".

Abbreviations: TJA, total joint arthroplasty; TXA, tranexamic acid.

who did and did not receive IV TXA. The pooled MD in the $\mathrm{Hb}$ level change was $-0.88 \mathrm{~g} / \mathrm{dL}(95 \% \mathrm{CI}=-1.31$ to $-0.44 \mathrm{~g} / \mathrm{dL}$, $P=0.001, I^{2}=83 \%$; Figure 3 ), as there was less $\mathrm{Hb}$ drop when revision TJA patients received IV TXA ( $3.18 \mathrm{~g} / \mathrm{dL}$ Hb drop) compared to control (4.06 g/dL Hb drop).

\section{Number of RBC units transfused per patient}

This outcome was measured in six studies. The number of RBC transfusions per patient was significantly lower in the TXA group ( 0.50 unit per person) compared to the control group (0.94 unit per person), with an MD of -0.44 units (95\% $\mathrm{CI}=-0.65$ to -0.24 units; $P=0.001, I^{2}=54 \%$; Figure 4 ).

\section{Blood loss}

Five studies provided data on blood loss. Two of them were EBL, while the others were TBL, intraoperative blood loss (IBL), and BLD. There was high statistical heterogeneity between studies $\left(P=0.001, I^{2}=87 \%\right)$. The meta-analysis (Figure 5) showed a slightly lower amount of blood loss with TXA use, but this did not reach statistical significance $(\mathrm{MD}=-245 \mathrm{~mL}, 95 \% \mathrm{CI}=-556$ to $66 \mathrm{~mL}$, $\left.P=0.123, I^{2}=82 \%\right)$.

\section{VTE complications}

Of the seven studies, five reported data on the proportion of patients who developed VTE complications. There were no significant differences between revision TJA with IV TXA $(3 / 436,0.69 \%)$ and without TXA $(5 / 383,1.31 \%$; OR=0.57, $95 \% \mathrm{CI}=0.13-2.42, P=0.45 ; I^{2}=0 \%$; Figure 6 ).

\section{Discussion}

There were significantly lower blood transfusion rates, less drop in $\mathrm{Hb}$ and less units of RBC units transfused when comparing IV TXA administration to control in revision TJA patients. Concomitantly, administration of IV TXA did not increase the rate of VTE in revision TJA patients compared to controls.

\begin{tabular}{|c|c|c|c|c|c|c|c|}
\hline $\begin{array}{l}\text { Group by } \\
\text { location }\end{array}$ & Study name & $\begin{array}{l}\text { Statistics for } \\
\text { Difference in } \\
\text { mean values }\end{array}$ & $\begin{array}{l}\text { ach study } \\
\text { Lower } \\
\text { limit }\end{array}$ & $\begin{array}{l}\text { Upper } \\
\text { limit }\end{array}$ & $P$-value & Difference in mean values and $95 \% \mathrm{Cl}$ & $\begin{array}{l}\text { Relative } \\
\text { weight }\end{array}$ \\
\hline Hip & Kazi et al $(2012)^{7}$ & -0.70 & -1.82 & 0.42 & 0.222 & 1 & 28.49 \\
\hline Hip & Park et al $(2016)^{12}$ & -1.51 & -1.93 & -1.09 & 0.000 & & 71.51 \\
\hline Subtotal & & -1.28 & -2.00 & -0.56 & 0.000 & & \\
\hline Knee & Smit et al $(2013)^{9}$ & -0.42 & -0.71 & -0.13 & 0.005 & & 62.27 \\
\hline Subtotal & & -0.64 & -1.19 & -0.09 & 0.023 & & \\
\hline \multirow[t]{3}{*}{ Overall } & & -0.88 & -1.31 & -0.44 & 0.000 & & \\
\hline & & & & & -2.00 & 1.00 & 2.00 \\
\hline & & & & & & Favor control & \\
\hline
\end{tabular}

Figure 3 Results of aggregate analysis for comparison of change in $\mathrm{Hb}$ levels between revision TJA patients who received intravenous TXA and control, including subgroup analysis by hip and knee.

Note: 95\% Cl shown as "Lower limit" and "Upper limit".

Abbreviations: Hb, hemoglobin; TJA, total joint arthroplasty; TXA, tranexamic acid. submit your manuscript | www.dovepress.com 


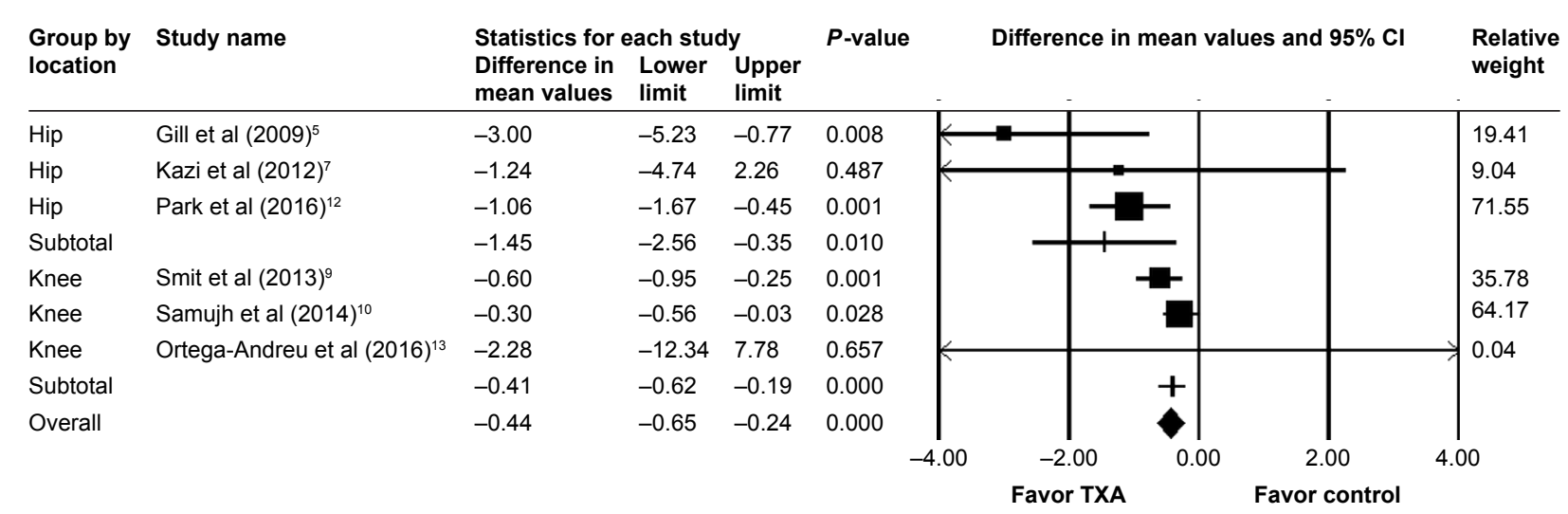

Figure 4 Results of aggregate analysis for comparison of RBC units transfused per patient between revision TJA patients who received intravenous TXA and control, including subgroup analysis by hip and knee.

Note: $95 \% \mathrm{Cl}$ shown as "Lower limit" and "Upper limit".

Abbreviations: RBC, red blood cell; TJA, total joint arthroplasty; TXA, tranexamic acid.

Systematic reviews and meta-analyses have demonstrated that IV TXA is efficacious at reducing blood loss and decreasing allogenic transfusion rates in primary TJA. ${ }^{3,17}$ This study is the first meta-analysis in revision TJA patients that demonstrated that IV TXA reduced allogenic blood transfusions in revision THA and revision TKA patients. However, our meta-analysis did not show that IV TXA significantly reduced blood loss in revision TJA. These results may be attributed to the fact that the measuring methods of blood loss were not consistent, as the most consistent method of blood loss measurement from the pooled studies was EBL. ${ }^{18}$ Blood loss measurement using IBL or drain blood loss were not reliable, as these measurements underestimated the true TBL from TJA, since hidden blood loss is calculated and makes up $\sim 50 \%$ of TBL. ${ }^{19}$ TXA can effectively decrease drainage blood loss by $\sim 50 \%$ in the postoperative period, but TXA has not been shown to significantly reduce hidden blood loss, which is not mediated in the initial phase of fibrinolysis. ${ }^{19}$
However, there was a trend toward IV TXA resulting in less blood loss, with an MD of $359 \mathrm{~mL}$ less blood loss in revision THA and $234 \mathrm{~mL}$ less blood loss in revision TKA.

IV TXA has been effectively shown to reduce $\mathrm{Hb}$ drop in primary TKA and THA. ${ }^{20,21}$ In a recent meta-analysis in primary TKA patients, IV TXA significantly reduced $\mathrm{Hb}$ loss compared to control patients who did not receive TXA $(\mathrm{MD}=-0.85, P=0.000,95 \% \mathrm{CI}=-1.26$ to -0.44$) .{ }^{20}$ In a metaanalysis of primary THA patients, the use of IV TXA reduced $\mathrm{Hb}$ loss up to $6.03 \mathrm{~g} / \mathrm{L}$ compared to that in controls $(P=0.001$, 95\% CI=3.90-8.15 g/L). ${ }^{21}$ In our meta-analysis, we also found a lower reduction in preoperative to postoperative $\mathrm{Hb}$ levels for IV TXA revision TJA patients ( $\mathrm{MD}=0.88 \mathrm{~g} / \mathrm{dL}$ ). In the four studies that were pooled, only one study did not have a significant difference in $\mathrm{Hb}$ change. ${ }^{7}$ Another study showed a significant difference in $\mathrm{Hb}$ change at 24 and 48 hours, but the $\mathrm{Hb}$ change at postoperative day 5 was not significant. ${ }^{13}$ Another study in THA patients demonstrated no difference

\begin{tabular}{|c|c|c|c|c|c|c|c|c|}
\hline $\begin{array}{l}\text { Group by } \\
\text { location }\end{array}$ & Study name & Outcome & $\begin{array}{l}\text { Statistics for } \\
\text { Difference in } \\
\text { mean values }\end{array}$ & $\begin{array}{l}\text { each stu } \\
\text { Lower } \\
\text { limit }\end{array}$ & $\begin{array}{l}\text { Idy } \\
\text { Upper } \\
\text { limit }\end{array}$ & $P$-value & Difference in mean values and $95 \% \mathrm{Cl}$ & $\begin{array}{l}\text { Relative } \\
\text { weight }\end{array}$ \\
\hline Нip & Kazi et al $(2012)^{7}$ & EBL & 28 & -183 & 239 & 0.795 & & 66.27 \\
\hline Hip & Gill et al $(2009)^{5}$ & TBL & $-1,119$ & $-2,419$ & 181 & 0.092 & & 33.73 \\
\hline Subtotal & & & -359 & $-1,422$ & 704 & 0.508 & & \\
\hline Knee & Aguilera et al $(2012)^{8}$ & EBL & -497 & -893 & -101 & 0.014 & & 24.82 \\
\hline Knee & Samujh et al $(2014)^{10}$ & IBL & 30 & -13 & 73 & 0.169 & & 38.93 \\
\hline Knee & Ortega-Andreu et al $(2016)^{13}$ & BLD & -338 & -486 & -190 & 0.000 & & 36.25 \\
\hline Subtotal & & & -234 & -560 & 91 & 0.159 & & \\
\hline \multirow[t]{3}{*}{ Over all } & & & -245 & -556 & 66 & 0.123 & & \\
\hline & & & & & & $-1,000$ & -500 & 1,000 \\
\hline & & & & & & & Favor control & \\
\hline
\end{tabular}

Figure 5 Results of aggregate analysis for comparison of blood loss between revision TJA patients who received intravenous TXA and control, including subgroup analysis by hip and knee.

Note: $95 \% \mathrm{Cl}$ shown as "Lower limit" and "Upper limit".

Abbreviations: BLD, blood loss via drainage; EBL, estimated blood loss; IBL, intraoperative blood loss; TBL, total blood loss; TJA, total joint arthroplasty; TXA, tranexamic acid. 


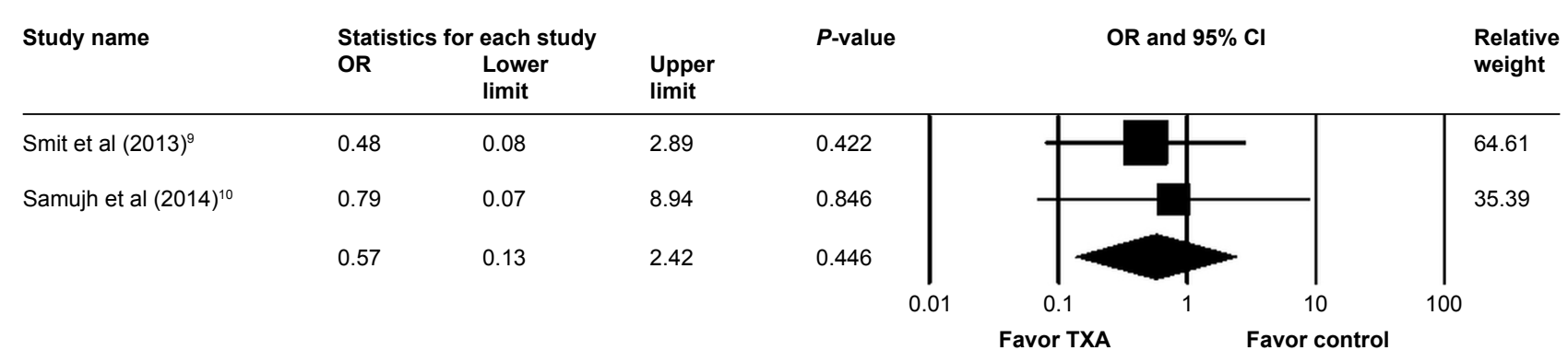

Figure 6 Results of aggregate analysis for comparison of VTE complications between revision TJA patients who received intravenous TXA and control. Note: $95 \% \mathrm{Cl}$ shown as "Lower limit" and "Upper limit".

Abbreviations: TJA, total joint arthroplasty; TXA, tranexamic acid; VTE, venous thromboembolism.

in $\mathrm{Hb}$ change on postoperative day $7 .{ }^{21}$ The $\mathrm{Hb}$ levels on postoperative days 5 and 7 may have been compensated by transfusions in the control group.

Reduction in allogenic RBC unit transfused per patient is also a concern in revision TJA. In primary THA, allogeneic $\mathrm{RBC}$ units transfused per patient was not significantly reduced in IV TXA patients compared to those in placebo (weighted $\mathrm{MD}=0.3$ units; $95 \% \mathrm{CI}=-0.49$ to 1.09 units, $P=0.45$ ) in a meta-analysis. ${ }^{21}$ However, there was a reduction in RBC units transfused per patient in primary TKA patients who received IV TXA (MD $=-1.14, P=0.000,95 \% \mathrm{CI}=-1.53$ to -0.76$).{ }^{20}$ This meta-analysis found that the number of RBC units transfused was significantly lower in the IV TXA group with a mean reduction of 0.44 unit per person $(P<0.001)$ compared to that in the control group in revision TJA cohorts.

However, concerns still exist regarding the safety of systemic TXA administration and the risk of VTE events in high-risk patients undergoing revision TJA. One recent review demonstrated no correlation between TXA and any major thromboembolic or nonthromboembolic complications in primary TJA. ${ }^{22}$ In a prospective randomized study, $\mathrm{Wu}$ et $\mathrm{al}^{11}$ reported that the combined administration of IV and topical TXA in revision THA did not increase the risk for VTE complications. Similarly, our meta-analysis also determined that IV administration of TXA did not increase the risk of VTE complication in revision TJA. Thus, TXA may be a relatively safe drug to administer during primary and revision TJA.

This study has several limitations. Of the seven studies, six were observational, resulting in some inherent heterogeneity due to uncontrolled bias. The heterogeneity of the included studies could explain the slight differences in factors affecting parameters of blood loss and postoperative complications, such as anesthesia type, surgical techniques, and operative time. Additionally, the type of revision TKA/THA (partial vs total) was not stratified in studies, which can also affect blood loss and blood transfusion rates due to differences in surgical exposure and operative time. We were also unable to differentiate between VTE complications, such as deep vein thrombosis and pulmonary embolism, as most studies reported aggregate VTE complications. The administration of IV TXA was heterogeneous with different dosages, and we cannot recommend a specific dosage of administration in revision TJA cases. The criteria for transfusion were also heterogeneous, which may affect outcomes. Finally, since we focused on IV TXA in this meta-analysis, we were unable to compare topical TXA to IV TXA in revision TJA.

\section{Conclusion}

Intravenous TXA reduced allogenic blood transfusions and had lower drop in Hb levels postoperatively without increasing VTE complications in patients undergoing revision TJA. Further prospective RCTs should be performed to examine the efficacy and safety of TXA in revision TJA patients.

\section{Acknowledgment}

We acknowledge and thank the Biostatistics Center at Kaohsiung Chang Gung Memorial Hospital for their statistical work.

\section{Disclosure}

The authors report no conflicts of interest in this work.

\section{References}

1. Kurtz S, Ong K, Lau E, Mowat F, Halpern M. Projections of primary and revision hip and knee arthroplasty in the United States from 2005 to 2030. J Bone Joint Surg Am. 2007;89(4):780-785.

2. Zufferey P, Merquiol F, Laporte S, et al. Do antifibrinolytics reduce allogeneic blood transfusion in orthopedic surgery? Anesthesiology. 2006;105(5):1034-1046.

3. Sukeik M, Alshryda S, Haddad FS, Mason JM. Systematic review and meta-analysis of the use of tranexamic acid in total hip replacement. J Bone Joint Surg Br. 2011;93(1):39-46.

4. Harkness M, Palmer JB, Watson D, Walsh TS. A questionnaire-based survey of perioperative blood conservation practice for revision hip arthroplasty in Scotland. Transfus Med. 2008;18(5):296-301. 
5. Gill JB, Chase E, Rosenstein AD. The use of tranexamic acid in revision total hip arthroplasty: a pilot study. Curr Orthop Pract. 2009;20(2): $152-156$.

6. Noordin S, Waters TS, Garbuz DS, Duncan CP, Masri BA. Tranexamic acid reduces allogenic transfusion in revision hip arthroplasty. Clin Orthop Relat Res. 2011;469(2):541-546.

7. Kazi HA, Fountain JR, Thomas TG, Carroll FA. The effect of bolus administration of tranexamic acid in revision hip arthroplasty. Hip Int. 2012; 22(6):615-620.

8. Aguilera X, Videla S, Almenara M, Fernandez JA, Gich I, Celaya F. Effectiveness of tranexamic acid in revision total knee arthroplasty. Acta Orthop Belg. 2012;78(1):68-74.

9. Smit KM, Naudie DD, Ralley FE, Berta DM, Howard JL. One dose of tranexamic acid is safe and effective in revision knee arthroplasty. $J$ Arthroplasty. 2013;28(8 Suppl):112-115.

10. Samujh C, Falls TD, Wessel R, Smith L, Malkani AL. Decreased blood transfusion following revision total knee arthroplasty using tranexamic acid. J Arthroplasty. 2014;29(9 Suppl):182-185.

11. Wu YG, Zeng Y, Yang TM, Si HB, Cao F, Shen B. The Efficacy and Safety of Combination of Intravenous and Topical Tranexamic Acid in Revision Hip Arthroplasty: A Randomized, Controlled Trial. J Arthroplasty. 2016;31(11):2548-2553.

12. Park KJ, Couch CG, Edwards PK, Siegel ER, Mears SC, Barnes CL. Tranexamic Acid Reduces Blood Transfusions in Revision Total Hip Arthroplasty. J Arthroplasty. 2016;31(12):2850-2855.

13. Ortega-Andreu M, Talavera G, Padilla-Eguiluz NG, et al. Tranexamic acid in a multimodal blood loss prevention protocol to decrease blood loss in revision total knee arthroplasty: a cohort study. Open Orthop J. 2016;10:439-447.
14. Phillips SJ, Chavan R, Porter ML, et al. Does salvage and tranexamic acid reduce the need for blood transfusion in revision hip surgery? J Bone Joint Surg Br. 2006;88(9):1141-1142.

15. Jadad AR, Moore RA, Carroll D, et al. Assessing the quality of reports of randomized clinical trials: is blinding necessary? Control Clin Trials. 1996;17(1):1-12.

16. Bae JM. A suggestion for quality assessment in systematic reviews of observational studies in nutritional epidemiology. Epidemiol Health. 2016;38:e2016014.

17. Gandhi R, Evans HM, Mahomed SR, Mahomed NN. Tranexamic acid and the reduction of blood loss in total knee and hip arthroplasty: a meta-analysis. BMC Res Notes. 2013;6:184.

18. Gibon E, Courpied JP, Hamadouche M. Total joint replacement and blood loss: what is the best equation? Int Orthop. 2013;37(4):735-739.

19. Good L, Peterson E, Lisander B. Tranexamic acid decreases external blood loss but not hidden blood loss in total knee replacement. $\mathrm{Br} J$ Anaesth. 2003;90(5):596-599.

20. Wu Q, Zhang HA, Liu SL, Meng T, Zhou X, Wang P. Is tranexamic acid clinically effective and safe to prevent blood loss in total knee arthroplasty? A meta-analysis of 34 randomized controlled trials. Eur J Orthop Surg Traumatol. 2015;25(3):525-541.

21. Zhou XD, Tao LJ, Li J, Wu LD. Do we really need tranexamic acid in total hip arthroplasty? A meta-analysis of nineteen randomized controlled trials. Arch Orthop Trauma Surg. 2013;133(7):1017-1027.

22. Lin ZX, Woolf SK. Safety, Efficacy, and Cost-effectiveness of Tranexamic Acid in Orthopedic Surgery. Orthopedics. 2016;39(2): $119-130$.
Drug Design, Development and Therapy

\section{Publish your work in this journal}

Drug Design, Development and Therapy is an international, peerreviewed open-access journal that spans the spectrum of drug design and development through to clinical applications. Clinical outcomes, patient safety, and programs for the development and effective, safe, and sustained use of medicines are the features of the journal, which

\section{Dovepress}

has also been accepted for indexing on PubMed Central. The manuscript management system is completely online and includes a very quick and fair peer-review system, which is all easy to use. Visit http://www.dovepress.com/testimonials.php to read real quotes from published authors. 